\title{
Rare association: sporadic lymphangioleiomyomatosis and Pi-SZ alpha-1-antitrypsin deficiency
}

\author{
Ashley Eve Eisner, ${ }^{1}$ Karanpal Sandhu, ${ }^{2}$ Kimberley $\mathrm{Cao}^{2}$
}

${ }^{1}$ Internal Medicine, University of South Florida, Tampa, Florida, USA

${ }^{2}$ Pulmonary and Critical Care Medicine, University of South Florida, Tampa, Florida, USA

\section{Correspondence to} Dr Ashley Eve Eisner; ashleyeveeisner@gmail.com

Accepted 26 March 2020

\section{DESCRIPTION}

We present a case of a 32-year-old Caucasian woman with Pi-SZ alpha-1-antitrypsin deficiency and sporadic lymphangioleiomyomatosis (LAM). The patient is a lifelong non-smoker with no exposure history. She has no known history of tuberous sclerosis or cirrhosis, nor a family history of lung disease. She came to be diagnosed with LAM and alpha-1 antitrypsin deficiency in her early 30 s after developing progressive dyspnoea. Initially, she had a CT chest performed after a motor vehicle accident that showed incidental ground glass changes, at this time she was asymptomatic. However, over the following months, her dyspnoea progressed, necessitating further workup. Subsequent CT chest showed macronodular changes concerning for panacincar emphysema along with apical cysts (figures 1 and 2). Laboratory testing revealed heterozygosity for PiSZ alpha-1 antitrypsin deficiency and an
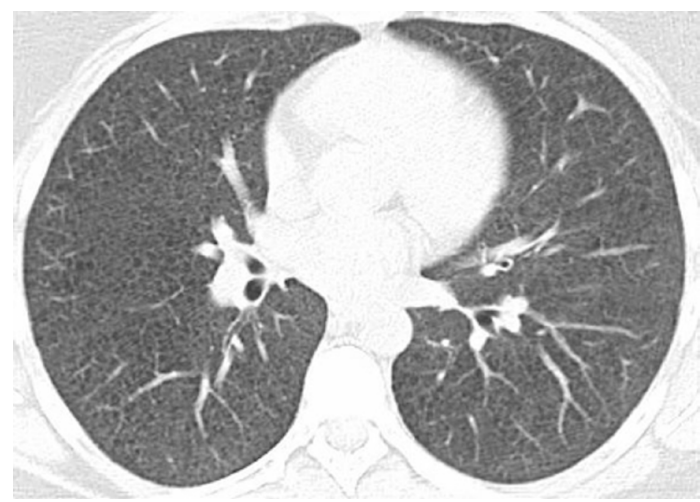

Figure 1 Representative slice from complete CT chest scan illustrating innumerable cystic changes of the pulmonary parenchyma.

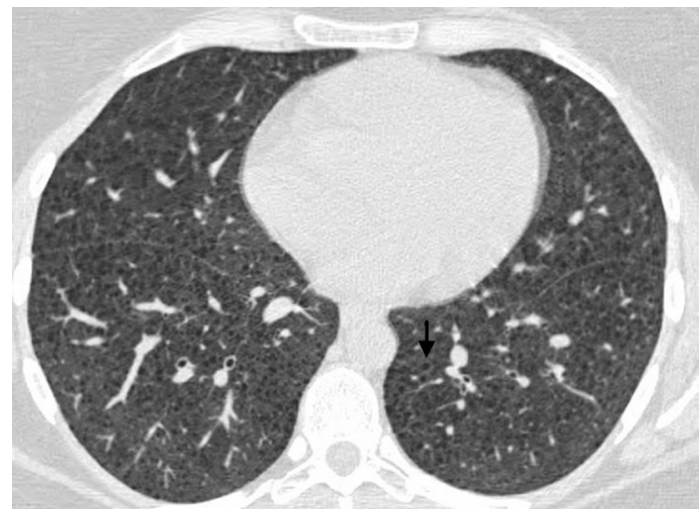

Figure 2 Representative slice from CT angiogram (CTA) chest scan demonstrating apical cysts.

\section{Patient's perspective}

It has definitely been a challenge learning my limitations as well as grasping the severity of my medical conditions. I honestly think it's been more difficult than anything to realise the gravity of what my current health condition entails. It's an ongoing process which I am sure will continue for some time.

\section{Learning points}

- Seemingly discrete conditions can share a common link, and this can have meaningful implications on disease management.

- Although further research is needed, the link between the imbalance of the alpha-1 antitrypsin and elastase system serves as an area of potential-perhaps expanding treatment options for diseases with currently limited therapeutics.

- When viewing imaging, it is important to keep in mind that the resolution (both of the $\mathrm{CT}$ and the computer screen) can make the difference between visualising intricacies such as small cysts and completely missing them.

elevated vascular endothelial growth factor D (VEGF-D) consistent with LAM in the context of cystic lung disease. She was initiated on weekly alpha-1 protease inhibitor injections.

Alpha-1 antitrypsin deficiency is an inherited disorder causing chronic obstructive pulmonary disease. It is thought to result from an imbalance between destruction and protection against proteolytic degradation of elastin. Sporadic LAM is a rare disorder that is radiographically characterised by lung cysts. It typically presents in young women as unexplained dyspnoea, spontaneous pneumothorax or chylous pleural effusions. To date, the combination of alpha-1-antitrypsin deficiency and LAM has only been described in one other case report. ${ }^{1}$ Whether the association between alpha-1 anti-trypsin deficiency and LAM is merely random or can be tied to a common genetic or pathophysiological phenomenon remains to be seen. Interestingly, recent research in LAM has shown that a degradation of elastic fibres occurs in addition to proliferation of smooth muscle. This combination of processes is thought to lead to the characteristic cystic changes visualised on imaging. ${ }^{2}$ The development of these cysts is thought to be secondary to an 
imbalance in the alpha- 1 antitrypsin and elastase system, potentially linking the two disease processes.

Contributors AEE wrote the body of the text, which was edited by KS and KC. Images were provided by KS. Educational points were provided by KC and KS.

Funding The authors have not declared a specific grant for this research from any funding agency in the public, commercial or not-for-profit sectors.

Competing interests None declared.
Patient consent for publication Obtained.

Provenance and peer review Not commissioned; externally peer reviewed.

\section{REFERENCES}

1 Chan AL, Kwack S, Jones KD, et al. Lymphangioleiomyomatosis and SZ alpha(1)antitrypsin disease: a unique combination? Chest 2003;124:763-5.

2 Fukuda Y, Kawamoto M, Yamamoto A, et al. Role of elastic fiber degradation in emphysema-like lesions of pulmonary lymphangiomyomatosis. Hum Pathol $1990: 21: 1252-61$

Copyright 2020 BMJ Publishing Group. All rights reserved. For permission to reuse any of this content visit https://www.bmj.com/company/products-services/rights-and-licensing/permissions/

BMJ Case Report Fellows may re-use this article for personal use and teaching without any further permission.

Become a Fellow of BMJ Case Reports today and you can:

- Submit as many cases as you like

- Enjoy fast sympathetic peer review and rapid publication of accepted articles

- Access all the published articles

- Re-use any of the published material for personal use and teaching without further permission

Customer Service

If you have any further queries about your subscription, please contact our customer services team on +44 (0) 2071111105 or via email at support@bmj.com.

Visit casereports.bmj.com for more articles like this and to become a Fellow 